\title{
ANALISIS FINANSIAL PUPUK ORGANIK CAIR KELOMPOK TANI HUTAN KEMASYARAKATAN HARAPAN MAJU DI DESA MOBUI SEBAGAI UPAYA PENGEMBANGAN USAHA PERHUTANAN SOSIAL
}

\section{(Financial Analysis of Liquid Organic Fertilizer of the Harapan Maju Farmer Group in Mobui Village as a Social Forestry Business Development)}

\author{
Dian Charity Hidayat ${ }^{1}$, Retno Maryani ${ }^{1}$, Setiasih Irawanti ${ }^{2}$, Muhammad Luthfi Susanto ${ }^{3}, \&$ \\ Joko Ridho Witono ${ }^{4}$ \\ ${ }^{1}$ Pusat Penelitian dan Pengembangan Sosial Ekonomi Kebijakan dan Perubahan Iklim, Jl. Gunung Batu No. 5 \\ Bogor, Indonesia; email: dian.charity@gmail.com, retnomaryani@hotmail.com \\ ${ }^{2}$ Yayasan Sarana Wana Jaya, Jl.Ampera Raya No. 47, Ragunan, Pasar Minggu, Jakarta Selatan, Indonesia; \\ email: s_irawanti@yahoo.com \\ ${ }^{3}$ Sekretariat Direktorat Jenderal Penegakan Hukum Lingkungan Hidup dan Kehutanan, Gedung Manggala \\ Wanabakti, Jl. Gatot Subroto, Jakarta Pusat, Indonesia; email: mochammad_susanto@yahoo.com \\ ${ }^{4}$ Pusat Konservasi Tumbuhan Kebun Raya-LIPI, Jl. Ir. H. Juanda No. 13, Bogor, Indonesia; \\ email: jrwitono@yahoo.com
}

Diterima 9 November 2018, direvisi 6 Desember 2019, disetujui 29 Januari 2020

\begin{abstract}
Community Forest (CF) is a sustainable forest management scheme that involves local community in order to increase the level of community welfare. It is necessary to develop several business activities that are able to support forest ecology and improve the living standard of the community. These activities include making organic liquid fertilizer (POC). The purpose of this research is to analyze the business feasibility and business continuity of POC of farmer group Harapan Maju CF in the Mobui Village, Kembayan District, Sanggau Regency, West Kalimantan. Data were collected through interviews with the management of the joint business group (KUB) of Mobui Majua covering fixed and variable costs based on market prices. In this research, some assumptions that are in line with field conditions are used for financial and sustainability analysis of POC production. The result shows that the activity of making POC by Mobui Majua CF is financially feasible with a positive Net Present Value (NPV), Benefit Cost Ratio (BCR) of 1.56, Return on Investment (ROI) of 55.67\%, and Payback Period (PP) in 7.5 months. Human resources skill and capability, proper marketing strategy, effective institution and raw material supply certainty are influencing factors for the POC business sustainability
\end{abstract}

Keywords: Community forest; financial analysis; liquid organic fertilizer; social forestry.

\begin{abstract}
ABSTRAK
Hutan kemasyarakatan (HKm) merupakan skema pengelolaan hutan lestari bersama masyarakat dengan harapan dapat meningkatkan tingkat kesejahteraan masyarakat. Beberapa kegiatan usaha yang mampu mendukung ekologi hutan dan meningkatkan taraf hidup masyarakat harus dilakukan, seperti pembuatan pupuk organik cair (POC). Penelitian ini bertujuan untuk mengkaji kelayakan bisnis dan keberlangsungan usaha POC Kelompok Tani HKm Harapan Maju, Desa Mobui, Kecamatan Kembayan, Kabupaten Sanggau, Kalimantan Barat. Data penelitian yang mencakup biaya tetap dan variabel sesuai dengan harga pasar dikumpulkan melalui metode wawancara dengan pengurus kelompok usaha bersama (KUB) Mobui Majua. Beberapa asumsi yang sesuai dengan kondisi lapangan digunakan untuk analisis keuangan dan keberlanjutan usaha POC. Hasil analisis menunjukkan bahwa kegiatan pembuatan POC HKm Mobui Majua merupakan usaha yang menguntungkan dan layak secara finansial dengan Net Present Value (NPV) yang positif, Return on Investment (ROI) 55,67\%, Benefit Cost Ratio (BCR) 1,56, dan Payback Period (PP) dalam waktu 7,5 bulan. Keterampilan dan kemampuan sumber daya manusia, strategi pemasaran tepat, kelembagaan efektif dan kepastian pasokan bahan baku merupakan faktor berpengaruh atas keberlanjutan usaha POC ini.
\end{abstract}

Kata kunci: Analisis finansial; hutan kemasyarakatan; perhutanan sosial; pupuk organik cair. 


\section{PENDAHULUAN}

Penggunaan pupuk anorganik di Indonesia berfluktuatif dan cenderung meningkat setiap tahunnya. Sebagaimana terlihat dalam Gambar 1, konsumsi pupuk urea nasional mengalami peningkatan (Rusastra, Saptana, \& Djulin, 2005; Irawan, Setyorini, \& Rochayati, 2012). Namun demikian, penggunaannya yang berlebihan mengakibatkan terjadinya degradasi lahan akibat berkurangnya kandungan bahan organik tanah (Mujiono, Tarkojo, Suyono, \& Indaryanto, 2011; Simanjuntak, Lahay, \& Purba, 2013). Untuk mengatasi masalah tersebut, penggunaan pupuk organik yang dikombinasikan dengan metode tanam System of Rice Intensification (SRI) sangat diperlukan (Hanum, Guchi, \& Jamilah, 2016).

Berdasarkan komponen penyusunnya, pupuk organik terdiri dari pupuk organik padat dan pupuk organik cair (POC). Penggunaan POC efektif dan efisien pada pertumbuhan dan perkembangan sawi (Nasution, Mawarni, \& Meiriani, 2014), pisang barangan (Zaini, 2015), dan padi sawah (MS, 2013; Bahua, Gubali, Tolinggi, \& Mopangga, 2014; Hasan, Bahua, \& Nurmi, 2015; Safitri, Linda, \& Rahmawati, 2017).

POC dapat dibuat dari komposisi berbagai macam bahan limbah pertanian maupun peternakan. Pada tahun 2012, Kementerian Perindustrian mulai mengembangkan POC karena terbukti mampu meningkatkan kesuburan tanah, ekonomis, dan layak jual (Syafputri, 2014). Oleh karena itu, pembuatan dan penggunaan POC sangat disarankan guna meningkatkan produktivitas lahan sekaligus menumbuhkan wirausaha baru.

Kelompok tani hutan kemasyarakatan (HKm) Harapan Maju yang berlokasi di Desa Mobui, Kecamatan Kembayan, Kabupaten Sanggau, Kalimantan Barat, mempunyai anggota sebanyak 164 orang yang berasal dari dua dusun, yaitu Dusun Mobui dan Dusun Majua. HKm tersebut telah memiliki ijin untuk mengolah lahan sekitar 2.100 ha yang berada di hutan lindung (1.510

\section{Penggunaan Pupuk Anorganik}

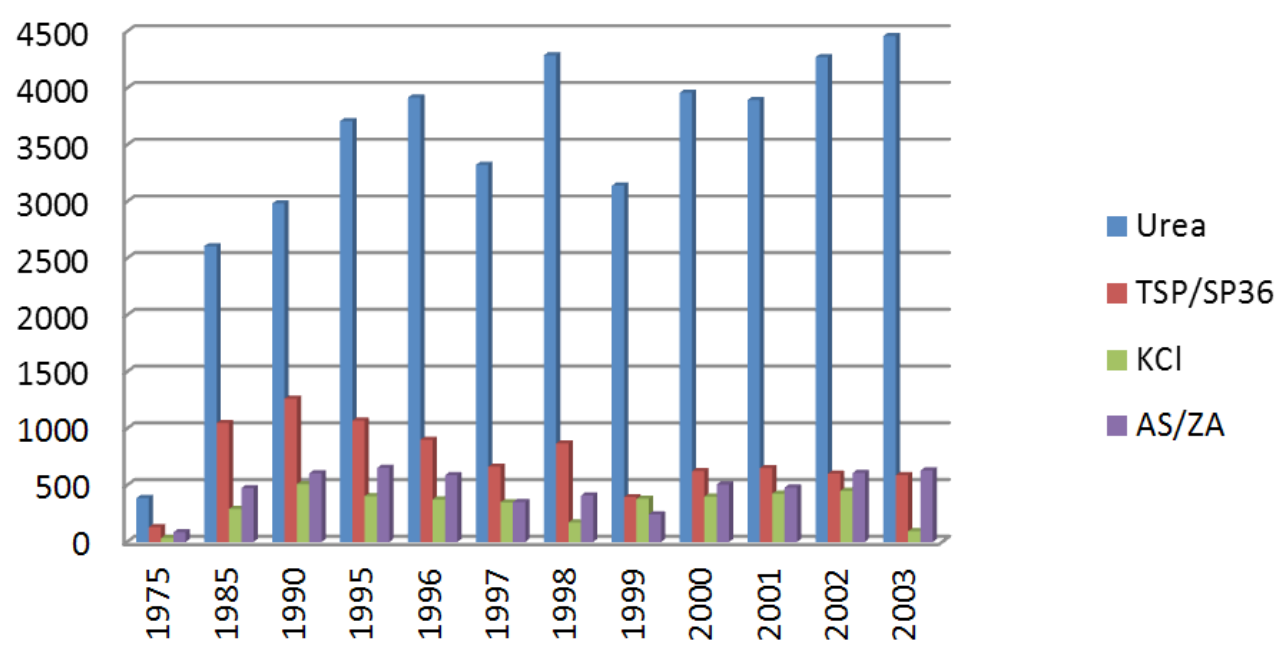

Sumber (Source): Fertilizer Hand Book (2003) dalam Rusastra, Saptana, \& Djulin (2005)

Gambar 1 Penggunaan pupuk di Indonesia dalam juta ton selama tahun 1975-2003

Figure 1 Picture of fertilizer utilization in million tons during 1975-2003. 
ha) dan hutan produksi (590 ha). Sebagian besar lahan garapan tersebut berupa tanah podsolik merah kuning yang umumnya ditanami karet, sedangkan sisanya berupa tanah berbatu dan rawa (Tim ITTO TFL-PD 32/13, 2017).

Kondisi tanah yang kurang subur di lokasi penelitian memerlukan pemupukan agar hasil produksi karet sesuai dengan yang diharapkan. Pemberian pupuk anorganik sebagai bagian dari penyuluhan budidaya tanaman pernah dilakukan. Relatif mahalnya harga pupuk anorganik tentunya dapat mengurangi keuntungan yang diperoleh petani. Pendapatan sebagian besar petani Desa Mobui (95\%) berasal dari budidaya dan penjualan getah karet yang produksinya sekitar $8-10 \mathrm{~kg} / \mathrm{hari}$ dengan harga jual $\mathrm{Rp} 8.000 / \mathrm{kg}$ sehingga diperkirakan pendapatan rata-rata petani sebesar Rp732.000/bulan (Tim ITTO TFLPD 32/13, 2017). Pendapatan tersebut masih di bawah Upah Minimum Kabupaten Sanggau yang \pm Rp1,9 juta/bulan (Keputusan Gubernur Kalimantan Barat Nomor 783/DISNAKERTRANS/2016). Sebagai alternatif, petani dapat membuat pupuk organik dengan bahan yang mudah diperoleh dan lebih murah.

Pemupukan perlu dilakukan terlebih lagi pada jenis tanah podsolik merah kuning yang dominan di wilayah Sanggau. Jenis tanah tersebut memiliki tingkat kesuburan dan pH yang rendah (Sembiring, 2008). Dalam pengelolaan tanah tersebut untuk tanaman pangan perlu dilakukan pemupukan, pengapuran, dan sistem pertanaman lorong (Prasetyo \& Suriadikarta, 2006). Kenyataannya, sebagian besar petani Desa Mobui dan Desa Majua lebih senang melakukan perladangan berpindah di kawasan hutan dan akan kembali menggarap lahan semula setelah tanahnya subur kembali.

Kelompok Usaha Bersama (KUB) Mobui Majua yang dibentuk dan diinisiasi oleh proyek ITTO tahun 2017, didorong untuk mengelola rumah produksi POC. Sebagai langkah awal proses produksi POC, diperlukan analisis kelayakan usaha guna kelangsungan usaha tersebut. Keuntungan dari produksi POC diharapkan mampu meningkatkan pendapatan petani, selain pendapatan dari bercocok tanam. Terlebih lagi, penggunaan POC dapat mengubah pola perladangan berpindah menjadi budidaya tanaman dengan pemupukan organik. Usaha POC tersebut dinilai mampu mendukung kegiatan HKm dari aspek ekonomi, sosial, dan ekologi. Pengelolaan hutan lestari yang berkelanjutan merupakan kunci keberhasilan program $\mathrm{HKm}$ yang merupakan bagian dari program perhutanan sosial. Untuk itu, keberlanjutan usaha produksi POC perlu diketahui dan diimplementasikan.

Penelitian bertujuan untuk menganalisis kelayakan finansial produksi POC dan keberlangsungan usaha tersebut. Guna memastikan keberlanjutan usaha POC, faktor-faktor yang mempengaruhi juga perlu diidentifikasi.

\section{METODE PENELITIAN}

\section{A. Waktu dan Lokasi Penelitian}

Kegiatan produksi POC dilakukan di Desa Mobui, Kecamatan Kembayan, Kabupaten Sanggau, Kalimantan Barat. Data yang dianalisis adalah data biaya yang diperlukan pada saat produksi perdana yaitu ketika pelatihan pembuatan POC bagi pengurus dan anggota KUB Mobui Majua pada tahun 2017.

\section{B. Pengumpulan Data}

Data biaya tetap dan biaya variabel sesuai dengan harga pasar dikumpulkan pada saat pelatihan pembuatan POC. Data tersebut diambil melalui wawancara dengan 4 orang pengurus KUB Mobui Majua. Data sekunder yang dikumpulkan berupa informasi yang terkait dengan dokumen perijinan, peraturan daerah, tingkat suku bunga, dan harga pasar POC. 


\section{Analisis Data}

\section{Analisis Keuntungan}

Analisis keuntungan mencakup perhitungan laba dan harga pokok produksi.

\section{a. Perhitungan Laba}

Keuntungan usaha dihitung dari selisih penerimaan dengan biaya usaha. Perhitungan laba dihitung dengan persamaan (Diatin, Moch, \& Irianni, 2007; Darwis, 2014):

$\pi=\mathrm{TR}-\mathrm{TC}$

di mana:

$\pi \quad$ : Keuntungan (rupiah)

TR : Total revenue (rupiah)

TC : Total cost (rupiah)

b. Harga Pokok Produksi (HPP)

Penentuan HPP menggunakan metode full costing di mana biaya tetap dan variabel diperhitungkan, namun tidak memasukkan biaya administrasi dan umum (Batubara, 2013):

$\mathrm{HPP}=\frac{\mathrm{FC}+\mathrm{VC}-\mathrm{AC}}{\mathrm{N}}$

di mana:

FC : Fix cost $(\mathrm{Rp})$

$\mathrm{VC}:$ Variable cost (Rp/unit)

$\mathrm{AC}:$ Administration cost (Rp)

$\mathrm{N}$ : Production unit

\section{Analisis Kelayakan Usaha}

Analisis kelayakan usaha dapat digunakan untuk memprediksi keberlangsungan usaha POC. Indikator yang digunakan dalam analisis yaitu Break Event Point (BEP), Net Present Value (NPV), Payback Period (PP), Benefit Cost Ratio (BCR), dan Return on Investment (ROI).

\section{a. Break Event Point (BEP)}

Break Event Point/BEP (titik impas) merupakan total biaya dan total benefit yang sama besar yang mencakup nilai rupiah dan jumlah unitnya. Indikator ini dihitung untuk mengetahui jumlah penjualan minimum agar tidak mengalami kerugian.
1) BEP Dalam Satuan Unit

BEP Unit $=\frac{F C}{P-V C}$

di mana:

FC : Fix cost (Rp)

$\mathrm{P}$ : Harga output (Rp/unit)

$\mathrm{VC}$ : Variable cost (Rp/unit)

Biaya variabel didapatkan dari perhitungan berikut:

$\mathrm{VC}=\frac{\mathrm{TVC}}{\mathrm{n}}$

di mana:

TVC : Total variable cost

$\mathrm{n} \quad$ : unit

2) BEP Dalam Satuan Rupiah (Wijana, Triadi, \& Kholiq, 2015)

BEP rupiah $=\frac{\mathrm{FC}}{\left(1-\frac{\mathrm{VC}}{\mathrm{P}}\right)}$

di mana:

FC : Fix cost $(\mathrm{Rp})$

$\mathrm{VC}$ : Variable cost (Rp/unit)

$\mathrm{P} \quad$ : Harga output (Rp/unit)

\section{b. Net Present Value (NPV)}

Kelayakan usaha dapat dilihat dari nilai NPV. Jika nilai NPV positif $>0$, maka usaha tersebut layak (Kusumedi \& Jariyah, 2010). Adapun formulasinya adalah sebagai berikut:

$\mathrm{NPV}=\sum \frac{B_{\mathrm{t}-} C_{\mathrm{t}}}{(1+\delta)^{\mathrm{t}}}$

di mana :

$\mathrm{B}_{\mathrm{t}}$ : Keuntungan periode tertentu (rupiah)

$\mathrm{C}_{\mathrm{t}}$ : Biaya periode tertentu (rupiah)

$\delta$ : Tingkat diskonto

$\mathrm{t}$ : Waktu (tahun)

\section{c. Payback Period (PP)}

Jangka waktu yang digunakan untuk mengetahui berapa lama usaha produksi POC yang dikerjakan dapat mengembalikan investasi, digunakan analisis PP dengan persamaan (Diatin et al., 2007):

$$
\begin{aligned}
& \mathrm{PP}=\frac{\text { investasi awal x periode }}{\text { keuntungan }} \text {............(7) } \\
& \text { di mana: } \\
& \text { - Periode merupakan periode akuntansi yang } \\
& \quad \text { digunakan dan penelitian ini menggunakan }
\end{aligned}
$$


periode 1 tahun

- Investasi awal meliputi pembelian peralatan dan aset yang digunakan pada awal usaha.

\section{d. B/C Ratio (BCR)}

Keuntungan usaha per periode dapat dilihat dari BCR yang merupakan perbandingan present value (PV) benefit dan PV biaya. Apabila BCR $>1$ berarti produksi POC menguntungkan secara finansial (Kusumedi \& Jariyah, 2010).

$\mathrm{BC}$ ratio $=\frac{(\mathrm{PV}) \mathrm{B}}{(\mathrm{PV}) \mathrm{C}}$

di mana:

(PV) B: Present value benefit (Rupiah)

(PV) C: Present value cost (Rupiah)

\section{e. Return on Investment (ROI)}

ROI digunakan untuk melihat kemampuan atas biaya yang telah dikeluarkan untuk mendapatkan keuntungan. ROI dihitung dengan persamaan (Marsudi, 2011):

ROI $=\frac{P \cdot Q-\sum r_{i} X_{i}}{\sum r_{i} X_{i}} \times 100 \%$

di mana:

$\mathrm{P} \quad$ : Price (rupiah)

Q : Quantity (botol/liter)

$\mathrm{r}_{\mathrm{i}} \mathrm{X}_{\mathrm{i}}$ : Production cost (rupiah)

\section{Analisis Sensitivitas}

Analisis sensitivitas adalah analisis yang digunakan untuk melihat keberlanjutan usaha pada saat terjadi kenaikan harga. Dalam kajian ini, terdapat beberapa skema analisis, yaitu pada kondisi:

a. Harga input naik $10 \%$ dan output tetap

b. Harga output turun $10 \%$ dan input tetap

c. Harga input naik $10 \%$ dan output turun $10 \%$.

Estimasi nilai kenaikan dan penurunan pada tingkat $10 \%$ yang digunakan mengacu pada rata-rata laju inflasi tiap tahunnya. Guna melihat apakah dalam kondisi tersebut usahatani masih layak, nilai NPV, BCR, dan ROI pada masing-masing kondisi dapat menjadi bahan pertimbangan.

\section{III.HASIL DAN PEMBAHASAN}

\section{A. Proses Produksi}

Proses produksi POC dari input bahan baku hingga produk yang siap dipasarkan membutuhkan waktu sekitar 1,5 bulan. Dengan asumsi bahwa terdapat jeda dalam proses produksi berikutnya, maka dalam satu tahun direncanakan tujuh kali produksi. Adapun proses pembuatannya sesuai alur pada Gambar 2.

\begin{tabular}{|c|c|c|c|}
\hline $\begin{array}{l}\text { Bahan baku } \\
\text { - Kotoran sapi } \\
\text { - Kotoran kambing }\end{array}$ & \multirow{4}{*}{$\begin{array}{r}\vec{b} \\
\end{array}$} & $\begin{array}{l}\text { Pencampuran } \\
\text { Semua bahan dicampur rata, } \\
\text { dimasukkan ke dalam drum }\end{array}$ & \multirow{2}{*}{$\begin{array}{l}\text { Tahap 1 } \\
\text { Pada hari ke-11 dilakukan } \\
\text { penambahan air, dilakukan } \\
\text { fermentasi selama } 21 \text { hari }\end{array}$} \\
\hline $\begin{array}{l}\text { - Tepung arang } \\
\text { - Nasi }\end{array}$ & & & \\
\hline - Dedak & & & Tahap 2 \\
\hline $\begin{array}{l}\text { - Air bersih } \\
\text { - Bonggol pisang }\end{array}$ & & $\begin{array}{l}\text { Tahap } 3 \\
\text { - Dilakkukan nenambahan. }\end{array}$ & $\begin{array}{l}\text { o Starter } \\
\text { o Hormon }\end{array}$ \\
\hline $\begin{array}{l}\text { Pengemasan } \\
\text { - Pengisian dalam botol } \\
\text { - Pelabelan } \\
\text { - Pengemasan dalam dus }\end{array}$ & 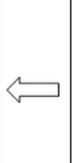 & $\begin{array}{l}\text { OStarter } \\
\text { - Dilakukan fermentasi } \\
\text { selama } 7 \text { hari } \\
\text { - Diperas, masuk ke proses } \\
\text { kemasan }\end{array}$ & $\begin{array}{l}\text { OKotoran kambing } \\
\text { - Kotoran kelelawar } \\
\text { - silakukan fermentasi } \\
\text { - Diperas, masuk } 7 \text { hahap } 3\end{array}$ \\
\hline
\end{tabular}

Sumber (Source): Tim ITTO TFL-PD 32/13 (2017)

Gambar 2 Proses produksi POC

Figure 2 The process of POC production. 
Proses pertama adalah pengumpulan bahan baku berupa kotoran kambing, kotoran sapi, dan urin sapi. Bahan tambahan lainnya adalah gula merah, beras, bekatul, dan tepung arang. Bahan baku yang digunakan relatif mudah didapatkan karena berasal dari limbah peternakan kambing dan sapi. Urin sapi, salah satu bahan pembuat POC, terbukti mempunyai unsur hara C-organik, nitrogen, fosfor, dan kalium (Kun Budi, 2011). Proses selanjutnya adalah pencampuran bahan baku dengan beberapa mikroba, di antaranya Azopirillum sp., Chitopaga sp., Pseudomonas sp., Basilus sp., Streptomyces sp., Saccharomyces sp., dan Azotobacter sp. melalui proses fermentasi, nitrifikasi, dan amonifikasi selama 21 hari. Pada hari ke-11 dilakukan penambahan air. Setelah proses fermentasi tahap 1 selesai, ditambahkan bahan starter, vitamin, kotoran kambing, dan kotoran guano. Setelah itu, dilakukan proses fermentasi tahap 2 selama 7 hari. Vitamin dan starter kembali ditambahkan sebelum tahap fermentasi 3. Setelah 7 hari proses fermentasi ke-3 selesai, dilakukan pengemasan dan pelabelan. Tenaga kerja yang dibutuhkan untuk menghasilkan 1.000 liter POC \pm 10 orang dengan 8 hari kerja efektif.

Tenaga kerja tersebut adalah anggota kelompok tani KUB Mobui Majua yang mempunyai keterampilan, kemampuan, kedisiplinan, dan komitmen tinggi untuk bekerja sama dalam pembuatan POC. Sistem kerja shift dan penjadwalan diaplikasikan, mengingat pekerjaan ini bukanlah pekerjaan utama bagi para anggota KUB yang mata pencaharian utamanya adalah petani. Dengan penjadwalan kerja, baik produktivitas usaha maupun kesehatan dan keselamatan pekerja dapat tetap terjaga (Aminia, Rahman, \& T, 2013). Anggota wanita juga mempunyai kesempatan untuk berpartisipasi dalam pekerjaan ini. Menurut Sofyan, Machfud, \& Mulyani (2017), 70\% anggota kelompak tani wanita mampu berpartisipasi dan terampil dalam pembuatan pupuk cair berbasis urin dan mikroorganisme lokal dan berpotensi sebagai sarana promosi mitra. Proses produksi dilakukan oleh anggota kelompok tani KUB Mobui Majua dan dilakukan di balai milik KUB sehingga biaya sewa ataupun bangunan tidak dicatat dalam perhitungan.

\section{B. Analisis Keuntungan Usaha}

Untuk menghasilkan 1.000 liter POC, dibutuhkan biaya variabel sebesar Rp22.808.000 dan biaya tetap sebesar Rp18.523.929. Biaya tetap tersebut terdiri dari biaya tenaga kerja, biaya utilities (pulsa telepon, gas, dan bensin untuk genset), serta biaya depresiasi. Biaya tenaga kerja merupakan gaji untuk pegawai tetap (bukan pegawai borongan) sehingga termasuk biaya tetap. Biaya tenaga kerja disesuaikan dengan UMR daerah yaitu Rp2 juta/bulan/orang. Total biaya yang dibutuhkan dalam satu kali proses produksi yaitu sebesar Rp41.331.929. Modal awal yang dibutuhkan untuk memulai usaha produksi POC adalah Rp61.465.000, berupa peralatan yang digunakan untuk usaha. Selain itu, perhitungan biaya depresiasi alat selama 3 tahun dan biaya depresiasi mesin selama 5 tahun juga dilakukan. Biaya depresiasi disesuaikan di akhir periode produksi dengan tujuan agar setelah 3 tahun peralatan dapat diperbaharui dan setelah 5 tahun mesin dapat diganti atau untuk membeli mesin baru yang dapat meningkatkan kapasitas produksi.

Hasil perhitungan harga pokok produksi POC disajikan pada Tabel 1. Sebagai dasar penentuan harga jual konsumen dan perencanaan laba, dapat digunakan harga pokok produksi (HPP) (Mulyadi, 2012). HPP diperhitungkan dengan menggambungkan semua elemen biaya, baik biaya tetap maupun variabel (Wardoyo, 2016), sedangkan selisih antara nilai jual dengan harga pokok adalah margin. Seberapa besar margin yang ditetapkan merupakan kebijakan kelompok usaha POC Harapan Maju. Besar margin tersebut juga dipengaruhi oleh strategi 
Tabel 1 Hasil perhitungan harga pokok produksi

Table 1 The calculation of cost of good manufactured

\begin{tabular}{lcc}
\hline \multicolumn{1}{c}{ Uraian (Description) } & Satuan (Unit) & Jumlah (Total) \\
\hline Kapasitas produksi (Production capacity) & liter & 1.000 \\
Kapasitas produksi (Production capacity) & Botol (Bottle) & 1.000 \\
Total biaya tetap (Fix cost) & $\mathrm{Rp} / \mathrm{bln}($ Rp/month) & 18.523 .929 \\
Total biaya variabel (Variable cost) & $\mathrm{Rp} / \mathrm{bln}($ Rp/month) & 22.808 .000 \\
Total biaya (Total cost) & $\mathrm{Rp} / \mathrm{bln}($ Rp/month) & 41.331 .929 \\
Harga pokok produksi (Cost of good sold) & $\mathrm{Rp} / \mathrm{liter}$ & 41.332 \\
Harga jual (Sale price) & $\mathrm{Rp} / \mathrm{liter}$ & 55.000 \\
Margin & $\mathrm{Rp} / \mathrm{liter}$ & 13.668 \\
Margin & $\%$ & 24,8 \\
\hline
\end{tabular}

Keterangan (Remarks): 1 liter $=1$ botol $($ bottle $)$.

Sumber (Sources): Data primer, diolah (Primary data, processed).

pemasaran yang digunakan untuk penetrasi pasar. Dan pada akhirnya besar margin yang diseting menentukan besar laba usaha.

Dengan asumsi 1 liter atau 1 botol POC dijual seharga Rp55.000, penjualan dalam satu kali proses produksi adalah Rp55.000.000. Apabila semua produk terjual maka keuntungan yang diperoleh adalah Rp13.668.071. Usaha POC masih diperkirakan menguntungkan dan layak apabila penjualan turun hingga $10 \%$ di mana NPV masih positif sebesar Rp314.612.007 pada 5 tahun ke depan. Oleh karena itu, peran-serta anggota Kelompok Tani Harapan Maju untuk menggunakan dan memasarkan produk POC sangat diperlukan.

Untuk mendapatkan laba usaha pada setiap kali produksi, satu botol POC harus dijual di atas HPP. Metode penentuan HPP tergantung dari produsen, apakah berorientasi kepada persaingan harga pasar atau keuntungan usaha. Guna menjamin keberlangsungan usaha POC, metode yang digunakan adalah metode full costing yaitu sebesar Rp41.332/botol. Harga tersebut masih di bawah harga pasar yaitu Rp60.000 Rp150.000/botol (Daftar Pupuk Organik Cair, 2018). Dari perhitungan harga pokok produksi tiap unitnya maka dapat diketahui besar margin per liter adalah Rp13.668 per liter atau $24,8 \%$.

\section{Analisis Kelayakan Usaha}

Break even point (BEP) sangat penting sebagai dasar dalam penentuan harga jual. Dengan harga jual Rp55.000/liter maka BEP per unit adalah 4.028 botol dan BEP (rupiah) adalah $\mathrm{Rp} 221.536 .795$. Hal ini berarti, agar mendapatkan laba dan balik modal maka KUB Mobui Majua setidaknya harus menjual lebih dari 4.028 botol atau mendapatkan nilai total hasil penjualan di atas Rp221.536.795. Berdasarkan hasil perhitungan finansial diketahui bahwa waktu pengembalian modal atau payback period (PP) tersebut adalah 0,64 atau setelah lima kali proses produksi atau $\pm 7,5$ bulan.

Hasil analisis menunjukkan bahwa proses produksi POC layak secara finansial karena mempunyai NPV yang positif yaitu Rp658.851.506 untuk 5 tahun ke depan. Usaha POC dapat dikatakan layak, menguntungkan, dan berkelanjutan, baik dalam jangka pendek (1 tahun) maupun jangka panjang (5 tahun). Hasil perhitungan $\mathrm{B} / \mathrm{C}$ ratio juga positif dengan nilai $>1$. Dalam perhitungannya digunakan asumsi discount rate $10 \%$. Tingkat diskonto tersebut disesuaikan dengan kisaran suku bunga kredit mikro di daerah penelitian pada saat penelitian dilakukan. Nilai ROI sebesar 55,67\% dapat diartikan bahwa setiap Rp100,00 yang dikeluarkan untuk membuat POC, keuntungan yang dapat dihasilkan 
Tabel 2 Hasil analisis finansial

Table 2 The result of financial analysis

\begin{tabular}{lcl}
\hline \multicolumn{1}{c}{ Analisis finansial (Financial analysis) } & Hasil (Result) & Interpretasi (Interpretation) \\
\hline BEP (unit) & 4.028 & \\
BEP (rupiah) & 221.536 .795 & \\
PP (bulan/month) & 7,5 & \\
NPV & Positif & Layak (Feasible) \\
B/C ratio & 1,56 & Layak (Feasible) \\
ROI (\%) & 55,67 & Layak (Feasible) \\
\hline
\end{tabular}

Sumber (Sources): Data primer, diolah (Primary data, processed).

adalah Rp55,00. Meskipun perhitungan tersebut belum memperhitungkan risiko kejadian luar biasa yang mungkin terjadi, asumsi discount rate $10 \%$ dapat mengantisipasi adanya inflasi yang terjadi pada tiap tahunnya. Dengan kata lain, meskipun terjadi inflasi, dalam 5 tahun ke depan, usaha POC ini diperkirakan masih dapat memberikan keuntungan usaha. Dengan demikian maka usaha produksi POC sangat layak untuk dijadikan usaha utama yang berkelanjutan bagi KUB Mobui Majua.

Hasil perhitungan kelayakan usaha yang positif dan perhitungan kembali modal setelah 5 kali produksi menunjukkan bahwa dalam periode kurang dari 1 tahun usaha produksi POC sangat layak. Usaha semacam ini sangat direkomendasikan bagi kelompok tani maupun kelompok tani hutan untuk swadaya pupuk organik.

Hasil penelitian tersebut menguatkan hasil penelitian Putra, Susilo, Nugroho, \& Ahmad (2014) mengenai analisis finansial limbah biogas menjadi pellet ikan dan pupuk organik cair yang menunjukkan bahwa usaha
POC layak dan menguntungkan dengan NPV Rp24.439.660,58; B/C ratio 1,25; IRR 50,97\%; dan PP 0,43.

\section{Analisis Sensitivitas}

Untuk melihat apakah usaha ini masih menguntungkan dan layak apabila terjadi kenaikan bahan baku (input), penurunan produksi (output), dan kondisi di mana kedua hal tersebut terjadi maka dilakukan analisis sensitivitas yang hasilnya dapat dilihat pada Tabel 3. Berdasarkan data BPS, rata-rata inflasi dari tahun 2002-2017 adalah $6,7 \%$ per tahun, namun untuk perencanaan keuangan dapat digunakan asumsi 7-10\% per tahun (Zh, 2017). Untuk itu, asumsi peningkatan harga input dan penurunan produksi yang digunakan dalam analisis adalah pada tingkat $10 \%$.

Dari Tabel 3 dapat dilihat bahwa apabila kondisi harga input bahan baku mengalami kenaikan sebesar 10\% maka produksi POC masih layak untuk diusahakan. Hal tersebut dapat dilihat dari nilai NPV yang positif 658.851.506,1 dan BCR >1 yaitu 1,21. Terlebih lagi, pengembalian atas investasi

Tabel 3 Hasil analisis sensitivitas

Table 3 Sensitivity analysis results

\begin{tabular}{lccc}
\hline \multicolumn{1}{c}{ Indikator keuangan (Financial Incdicator) } & NPV & BCR & ROI (\%) \\
\hline Ceteris paribus & $658.851 .506,1$ & 1,33 & 33,1 \\
Input naik 10\% (Input increases) & $351.896 .065,8$ & 1,21 & 21 \\
Output turun 10\% (Output decreases) & $286.010 .915,2$ & 1,2 & 19,8 \\
Input naik 10\% dan output turun 10\% (Input increases and & 5.825 .085 & 1,09 & 8,9 \\
output decreases) & & \\
\hline
\end{tabular}


masih di atas asumsi inflasi $10 \%$ yaitu pada tingkat pengembalian $21 \%$.

Pada kondisi jumlah produksi POC berkurang $10 \%$, produksi masih layak untuk dijalankan. Meskipun nilai NPV turun sebesar $56 \%$ dari kondisi NPV ceteris paribus, usaha POC masih dinilai layak. Hal ini didukung oleh nilai BCR yang masih $>1$ dan ROI sebesar 19,8\%, masih di atas asumsi inflasi.

Dari hasil analisis sensitivitas, usaha POC masih dinilai layak meskipun pada skenario kondisi di mana harga input meningkat dan produksi turun masing-masing pada tingkat $10 \%$. Hal ini dilihat dari NPV yang masih positif dan BCR $>1$ meskipun mendekati titik impas. Walaupun tingkat pengembalian atas investasi di bawah asumsi inflasi 10\%, secara keseluruhan produksi POC masih layak untuk dijalankan.

\section{E. Keberlanjutan Usaha}

Hasil analisis finansial menunjukkan bahwa proses produksi POC adalah layak secara finansial, namun kelayakan tersebut masih perlu keseriusan dan ketekunan dari ketua, pengurus, dan anggota KUB Mobui Majua. Agar proses produksi dapat dilaksanakan sesuai standar dan produk terjaga kualitasnya maka diperlukan pengaturan jadwal kerja dan beberapa pelatihan lanjutan seperti pelatihan kewirausahaan dan penyusunan rencana kerja. Terkait hal tersebut, menurut Ardiana, Brahmayanti, \& Subaedi (2010), aspek kemampuan seperti bakat, ketertarikan, keahlian, dan faktor pribadi paling berpengaruh terhadap kinerja di suatu usaha kecil menengah (UKM). Peningkatan sumberdaya manusia merupakan salah satu aspek penting dalam mengembangkan UKM (Sukesti, 2011).

Proses produksi POC tidak akan berlanjut tanpa pemasaran yang baik. Hal pertama yang dilakukan adalah pemenuhan administrasi untuk ijin edar, uji mutu, dan uji efektivitas kelayakan produk. POC telah diberikan ijin dengan nomor L.1005/ORGANIK/ DEPTAN-PPVTPP/IX/2011. Adapun kadar dan kandungan POC tersebut sesuai dengan Tabel4. Merek POC Kelompok Tani Harapan Maju sudah didaftarkan dengan nomor IDM 000338584. Dengan diperolehnya ijin-ijin tersebut, produk POC dapat dipasarkan kepada masyarakat Kalimantan Barat.

Strategi pemasaran dapat dilakukan dengan berbagai cara, seperti membuat warung penjualan di rumah produksinya, di kota kecamatan, atau di kota kabupaten. Apabila ada forum pameran, sosialisasi petani, pertemuan-pertemuan tingkat desa, penjualan POC dapat dilakukan dengan cara membuka lapak atau meja promosi. Apabila dimungkinkan, penjual POC dapat dilakukan secara online. Manfaat dan kemudahan penggunaan teknologi untuk penjualan online dapat meningkatkan kepuasan konsumen dan pembelian ulang produk yang ditawarkan (Ardiana et al., 2010). E-commerce, pemasaran produk melalui dunia maya, mempunyai cakupan luas dan dapat dilakukan kapan saja dan di mana saja (Jauhari, 2010). Selain itu, penggunaan media sosial secara optimal dan konsisten berpotensi meningkatkan volume penjualan dan pangsa pasar (Priambada, 2015).

Kelancaran proses pengadaan bahan baku (supply chain) juga perlu diperhatikan agar

Tabel 4 Komposisi kimia POC

Table 4 Chemical composition of POC

\begin{tabular}{lll}
\hline No. & Unsur (Ingredient) & \multicolumn{1}{c}{ Kadar (Content) } \\
\hline C-organic & $6,19 \%$ \\
$\mathrm{Fe}$ & $0,02 \%$ \\
$\mathrm{Cu}$ & $1,57 \mathrm{ppm}$ \\
$\mathrm{B}$ & $<1,0 \mathrm{ppm}$ \\
$\mathrm{Mo}$ & $<1,0 \mathrm{ppm}$ \\
$\mathrm{pH}$ & 4,78 \\
$\mathrm{Mn}$ & 65,23 \\
$\mathrm{Zn}$ & $5,76 \mathrm{ppm}$ \\
$\mathrm{Co}$ & $<1,0 \mathrm{ppm}$ \\
\hline
\end{tabular}

Sumber (Source): Dokumen sertifikat ijin edar (Distribution permit document). 
dapat memenuhi permintaan pasar secara berkesinambungan. Terlebih lagi, pasokan bahan baku adalah peluang usaha baru yang dapat dikerjakan oleh masyarakat sekitar, mitra usaha, atau KUB Mobui Majua. Manajemen pemasok merupakan hal yang penting karena merupakan salah satu faktor dari manajemen kualitas (Salaheldin dalam Ulfah, 2013). Demikian pula kelancaran pemasaran POC, juga sebuah peluang usaha baru yang dapat dilakukan oleh KUB Mobui Majua atau mitra usaha yang dapat menjalin kerjasama dengan KUB Mobui Majua.

Pembentukan KUB untuk usaha POC dharapkan efektif dalam memberdayakan masyarakat karena dibentuk sesuai kebutuhan ekonomi dan kondisi budaya masyarakat. Menurut Tampubolon, Sugihen, Samet, Susanto, \& Sumardjo (2007), keberhasilan KUB dipengaruhi oleh pembinaan kelompok, kepuasan anggota, kepemimpinan, keefektifan, kekompakan, tugas, dan tujuan kelompok. Untuk itu, pembinaan penguatan KUB Mobui Majua sangat diperlukan agar mekanisme pasar dapat berlangsung dan berkelanjutan.

Usaha POC ini diharapkan mampu memberikan efek pengganda (multiplier effects) pada masyarakat sekitar. Proses produksi POC akan memberi manfaat bagi masyarakat sekitarnya sehingga bisa menjadi pengungkit bagi tumbuhnya usahausaha pendukung lainnya. Pada akhirnya, masyarakat sekitar yang berkontribusi dapat memperoleh manfaat berupa penghasilan tambahan dari kegiatan pengumpulan limbah sebagai bahan baku pembuatan POC.

Sebagai gambaran, para peternak memperoleh manfaat ekonomi dari limbah padat maupun cair yang dihasilkan oleh hewan ternak. Petani memperoleh manfaat ekonomi dari limbah pohon pisang yang tumbuh di lahan mereka. Mereka juga dapat memperoleh manfaat ekonomi dengan cara membuat arang dari limbah kayu yang dikumpulkan dari kebun maupun hutan garapannya. Bekatul yang dihasilkan dari proses penggilingan gabah menjadi beras juga dapat mendatangkan manfaat ekonomi bagi petani. Selain itu, kebutuhan gula merah yang cukup besar juga membuka peluang usaha bagi petani yang memiliki pohon kelapa atau pohon aren karena dapat disadap niranya untuk membuat gula merah.

Untuk bahan baku pembuatan POC yang tidak tersedia di desa, akan membuka peluang bagi penduduk setempat untuk menjadi pedagang desa yang memasok kebutuhan bahan-bahan tersebut. Mempertimbangkan besarnya potensi limbah peternakan, pertanian, perkebunan, dan hutan, maka pendirian industri kecil POC seperti ini sangat potensial untuk dikembangkan di seluruh wilayah di Indonesia.

\section{KESIMPULAN DAN SARAN}

\section{A. Kesimpulan}

Proses produksi POC layak secara finansial karena mempunyai NPV yang positif, $\mathrm{B} / \mathrm{C}$ ratio $>1$, dan $\mathrm{ROI} 55,67 \%$ sehingga dapat dijadikan usaha utama bagi KUB Mobui Majua. Dengan harga jual POC sebesar Rp55.000/liter, usaha ini akan menghasilkan laba dan kembali modal apabila setidaknya dapat menjual lebih dari 4.028 botol atau mendapatkan nilai total hasil penjualan $>\operatorname{Rp} 221.536 .795$. Apabila proses produksi dan pemasaran POC berjalan lancar, maka lama pengembalian modal atau payback period (PP) adalah setelah lima kali proses produksi atau \pm selama 7,5 bulan.

Terdapat beberapa faktor yang mempengaruhi keberlanjutan usaha POC, di antaranya keterampilan dan kemampuan sumber daya manusia, strategi pemasaran yang tepat, dan kelembagaan yang efektif. Selain itu, pasokan bahan baku (supply chain) juga harus dipastikan dapat memenuhi target produksi POC.

\section{B. Saran}

Usaha POC layak dan dapat digunakan sebagai prototipe kegiatan pengembangan 
ekonomi di hutan kemasyarakatan (HKm) yang merupakan bagian dari Program Perhutanan Sosial Kementerian Lingkungan Hidup dan Kehutanan.

\section{UCAPAN TERIMA KASIH (ACKNOWLEDGEMENT)}

Ucapan terima kasih disampaikan kepada ITTO melalui Proyek ITTO TFLPD 32/13.Rev 2(M) "Penguatan Kapasitas Institusi Lokal untuk Mengelola Hutan Kemasyarakatan di Kabupaten Sanggau secara Lestari Guna Meningkatkan Kesejahteraan”. Kami mengucapkan terima kasih atas bantuan Tian Partiani dan Lisda (tim ITTO) yang telah mendukung kajian ini.

\section{DAFTAR PUSTAKA}

Aminia, E. F., Rahman, A., \& T, C. F. M. (2013). Penjadwalan tenaga kerja tiga shift berkendala libur hari Minggu dan satu hari setelah shift tiga. Rekayasa dan Manajemen Sistem Industri, 1(1), 22-30.

Anomim. (2018). Daftar Pupuk Organik Cair. Retrieved July 31,2018, from https://www. indotrading.com/showcase/pupuk-organikcair

Ardiana, I. D. K., Brahmayanti, I., \& Subaedi. (2010). Kompetensi SDM UKM dan pengaruhnya terhadap kinerja UKM di Surabaya. Jurnal Manajemen dan Kewirausahaan, 12(1), 4255. https://doi.org/10.9744/jmk.12.1.pp. 4255.

Bahua, M. I., Gubali, H., Tolinggi, W., \& Mopangga, H. (2014). Efektivitas pertumbuhan dan produksi padi sawah Oriza sativa L. melalui penggunaan pupuk organik cair POC di Kabupaten Gorontalo Utara. Gorontalo: Universitas Negeri Gorontalo.

Batubara, H. (2013). Penentuan harga pokok produksi berdasarkan metode full costing pada pembuatan etalase kaca dan aluminium di UD Istana Aluminium Manado. EMBA, 1(3), 217-224.

Darwis, V. (2014). Kajian analisis usahatani penggunaan pupuk organik non komersial terhadap hasil dan pendapatan petani padi. SEPA, 10(2), 286-297.
Diatin, I., Moch, P., \& Irianni, R. (2007). Analisis kelayakan finansial budidaya ikan nila wanayasa pada Kelompok Pembudidaya Mekarsari. Jurnal Akuakultur Indonesia, 6(1), 97-102.

Hanum, H., Guchi, H., \& Jamilah. (2016). Pengaruh pupuk anorganik dan organik terhadap sifat kimia tanah di lahan sawah dengan sistem tanam SRI dan konvensional (pp 148154). Prosiding Seminar Nasional Lahan Suboptimal, Palembang 20-21 Oktober 2016.

Hasan, F., Bahua, M. I., \& Nurmi. (2015). Efektivitas penggunaan pupuk organik cair (POC) terhadap pertumbuhan dan produksi padi sawah (Oryza sativa L.) (Karya Ilmiah Mahasiswa). Fakultas Ilmu Pertanian, Universitas Negeri Gorontalo.

Irawan, Setyorini, D., \& Rochayati, S. (2012). Proyeksi kebutuhan pupuk sektor pertanian melalui pendekatan sistem dinamis (pp. 123-139). Prosiding Seminar Nasional Teknologi Pemupukan dan Pemulihan Lahan Terdegradasi, Bogor, 29-30 Juni 2012. Bogor: Badan Penelitian dan Pengembangan Pertanian.

Jauhari, J. (2010). Upaya pengembangan usaha kecil menengah (UKM) dengan memanfaatkan e-commerce. Jurnal Sistem Informasi, 2(1), 159-168. https://doi.org/ISSN Online : 23554614.

Keputusan Gubernur Kalimantan Barat Nomor 783/ DISNAKERTRANS/2016 tentang Penetapan Upah Minimum Kabupaten Sanggau Tahun 2017.

Kun Budi, R. (2011). Studi pembuatan pupuk organik cair dari fermentasi urine sapi (Ferisa) dengan variasi lokasi peternakan yang berbeda. Semarang: Universitas Diponegoro.

Kusumedi, P., \& Jariyah, N. A. (2010). Analisis finansial pengelolaan agroforestri dengan pola sengon kapulaga di Desa Tirip, Kecamatan Wadaslintang, Kabupaten Wonosobo. Jurnal Penelitian Sosial dan Ekonomi Kehutanan, 7(2), 93-100.

Marsudi, E. (2011). Analisis keuntungan usaha pengolahan pupuk bokashi. Sains Riset, 1(2), $1-6$.

M S., Purwanti. (2013). Pertumbuhan karet (Hevea brasiliensis L.) asal okulasi pada pemberian bokashi dan pupuk organik cair Bintang Kuda Laut. AGRIFOR, XII(1), 35-44.

Mujiono, Tarkojo, Suyono, \& Indaryanto, S. B. (2011). Perakitan teknologi produksi padi organik berbasis pupuk organik cair pestisida nabati. Jurnal Agroland, 18(3), 162-168. 
Mulyadi. (2012). Akuntansi Biaya (5 $5^{\text {th }}$ ed.). Yogyakarta: UPP STM YKPN.

Nasution, F. J., Mawarni, L., \& Meiriani. (2014). Aplikasi pupuk organik padat dan cair dari kulit pisang kepok untuk pertumbuhan dan produksi sawi. Jurnal Online Agroekoteknologi, 2(2337), 1029-1037.

Prasetyo, B., \& Suriadikarta, D. (2006). Karakteristik, potensi, dan teknologi pengelolaan tanah ultisol untuk pengembangan pertanian lahan kering di Indonesia. Jurnal Litbang Pertanian, 25(2), 39-47. Retrieved from http://pustaka. litbang.deptan.go.id/publikasi/p3252061.pdf.

Priambada, S. (2015). Manfaat penggunaan media sosial pada usaha kecil menegah (UKM). Sesindo, (November), 2-3.

Putra, D. P., Susilo, B., Nugroho, W. A., \& Ahmad, A. M. (2014). Analisis finansial pengolahan limbah biogas menjadi pellet ikan dan pupuk organik cair. Keteknikan Pertanian Tropis dan Biosistem, 2(1), 53-64.

Rusastra, W., Saptana, \& Djulin, A. (2005). Roadmap pengembangan pupuk organik dalam mendukung pembangunan pertanian. Litbang Pertanian, 4, 167-211. Retrieved from http:// pse.litbang.pertanian.go.id/ind/pdffiles/ Anjak_2005_VI_05.pdf.

Safitri, A. D., Linda, R., \& Rahmawati. (2017). Aplikasi pupuk organik cair (poc) kotoran kambing difermentasikan dengan EM4 terhadap pertumbuhan dan produktivitas tanaman cabai rawit (Capsicum frutescents L.) Var . Bara. Protobiont, 6(3), 182-187.

Sembiring, H. (2008). Kebijakan penelitian dan rangkuman hasil penelitian $\mathrm{BB}$ Padi dalam mendukung peningkatan produksi beras nasional (pp. 39-59). Prosiding Seminar Apresiasi Hasil Penelitian Padi Menunjang P2BN, Subang, 19-20 November 2007. Subang: Balai Besar Penelitian Tanaman Padi.

Simanjuntak, A., Lahay, R. R., \& Purba, E. (2013). Respon pertumbuhan dan produksi bawang merah (Allium ascalonicum L.) terhadap pemberian pupuk NPK dan kompos kulit buah kopi. Jurnal Online Agroekoteknologi, 1(3), 362-373.

Sofyan, E. T., Machfud, Y., \& Mulyani, O. (2017). Pemberdayaan kelompok wanita tani dalam pembuatan pupuk organik cair ramah lingkungan di Cibiru Wetan. Jurnal Aplikasi Ipteks untuk Masyarakat, 6(3), 213-215. Retrieved from journdharmakarya/article/ viewFile/11437/5233al.unpad.ac.id/
Sukesti, F. (2011). Pemberdayaan UKM: Meningkatkan komoditas unggulan ekspor UKM dalam rangka pengembangan ekonomi daerah (studi pada UKM di Jawa Tengah). Makalah disajikan dalam Seminar Nasional Ilmu Ekonomi Terapan. Magelang, Universitas Muhamadiyah.

Syafputri, E. (2014). Koperasi petani minati pupuk organik cair. Diunduh 22 Juli 2018 dari Antaranews.com.

Tampubolon, J., Sugihen, B. G., Samet, M., Susanto, D., \& Sumardjo. (2007). Pemberdayaan masyarakat melalui pendekatan kelompok (kasus pemberdayaan masyarakat miskin melalui pendekatan kelompok usaha bersama/ KUBE). Jurnal Penyuluhan, 3(1), p.18-23. https://doi.org/1858-2664.

Tim ITTO TFL-PD 32/13. (2017). Data dasar sosial ekonomi HKm Sanggau (Laporan). Bogor: ITTO TFL-PD 32/13.

Ulfah, F. (2013). Analisis pengaruh implemantasi manajemen kualitas terhadap kinerja organisasi pada usaha kecil menengah (UKM) di Kota Salatiga. Semarang: Universitas Diponegoro.

Wardoyo, D. U. (2016). Analisis perhitungan harga pokok produksi dan penentuan harga jual atas produk (studi kasus pada PT Dasa Windu Agung). Jurnal Riset Manajemen dan Bisnis (JRMB) Fakultas Ekonomi UNIAT, 1(2), 183190.

Wijana, M., Triadi, A., \& Kholiq, M. (2015). Aplikasi break even point pada pembuatan roti, studi kasus usaha kecil menengah (UKM) roti (Rotiku Rotimu) Desa Babakan. Dinamika Teknik Mesin, 5(1), 2088-88.

Zaini, H. (2015). Pupuk organik cair dan pupuk organik padat bagi budidaya pisang barangan. Jurnal Handayani PGSD FIP UNIMED, 4(1).

Zh, R. (2017). Asumsi inflasi dan return reksa dana dalam perencanaan keuangan (1). Retrieved July 31, 2017, from https://ekonomi. kompas.com/read/2017/07/31/080000926/ asumsi-inflasi-dan-return-reksa-dana-dalamperencanaan-keuangan-1-?page=all. 